\title{
국제개발협력위원회 역할과 활동현황
}

박 종 민 KOICA 대리 (국무총리실 파견)

\section{I. 설립배경}

정부는 2005년 4월 30일 재원배분을 위한 국무위원 회의에서 $\mathrm{ODA}$ (공적개발원조) 운영체제 개선 을 전제로 2009 년까지 ODA 규모를 GNI 대비 $0.1 \%^{1}$ 까지 확대하기로 결정하였다. 정부는 2주일 뒤 2005년 5월13일 그 회의에 대한 후속조치로 국무조정실'에 관계부처와 관계기관, NGO가 공동 참여하는 ‘ODA 개선협의회’를 임시로 설치하였다. 협의회는 ODA 운영체제 개선을 위한 회의개최 와 여론조사, 해외실태조사, 연구용역을 실시하고, ODA 실태와 개선사항, 국제개발협력위원회 설 립 등의 내용을 담은 「대외원조 종합개선 대책 보고서」를 작성하였다.

2005년 11월15일에 종합개선 대책은 국무회의에 보고되고, 이어 2006년 1월26일에는 국제개발협 력위원회 규정(대통령령 제20724호)이 제정되어 국제개발협력위원회는 제도적 기반도 갖추게 되었 다. 그리고 2006년 3월2일 국제개발협력위원회는 제1차 회의를 열어 마침내 실질적인 출범을 하게 되었다.

국제개발협력위원회는 앞서 설명한 수순으로 설립되었지만, 사실상 너무 늦게 설립된 셈이다. 위 원회에 부여된 $\mathrm{ODA}$ 정책의 통합 - 조정기능은 오래 전부터 지적되어 왔던 문제이기 때문이다. $\mathrm{OECD}$ 개발원조위원회(DAC)와 시민사회, 학계 등에서는 이전부터 원조채널이 일관성 없이 분절화 (fragmentation) 된데 따른 우리나라 개발원조의 비효율성과 비효과성 문제를 지적해 왔다. 이와 함께 유사 사업의 중복 문제도 반복적으로 지적되어 왔다.

\section{II. 위원회 구성 및 역할}

국제개발협력위원회는 $\mathrm{ODA}$ 의 주요정책과 기본계획을 심의하기 위하여 국무총리 소속으로, 〈표 1〉

1) 당시 비교실적(2004년) : GNI 대비 $0.06 \%$

2) 정부조직법 개정(법률 제8852호, 2008.2.29)으로 국무조정실과 국무총리비서실이 국무총리실로 통합되었다. 
과 같이 위원장(국무총리) 1 인을 포함하여 총 21 인의 위원으로 구성되어 있다. 주목할 점은 위원회 에 시민사회 · 학계 · 경제계의 분야별 민간 전문가 6인(각 2인)이 포함되었다는 사실이다. ODA 최 상위 정책위원회에 민간위원을 참여시킨 이유는 국민 참여형 원조 추진 기반을 마련하고, 다양한 외부 전문가들의 의견 수렴을 통해 균형 있는 정부 ODA 정책을 수립하기 위한 것이다.

\section{〈표 1〉국제개발협력위원회 위원 구성 (2009년 9월 현재)}

\section{〈국제개발협력위원회 위원(21명)〉}

○ 위원장 : 국무총리

○ 정부위원 : 기획재정부 · 교육과학기술부 · 외교통상부 · 행정안전부 · 농림수산식품부 · 지식경 제부 · 보건복지가족부 · 환경부 · 노동부 · 여성부 ·

국토해양부장관 및 국무총리실장

○ 관계기관 : 한국국제협력단(KOICA) 이사장, 한국수출입은행장 (이상 당연직)

인간위원 : 이일하 굿네이버스 회장, 한비야 월드비젼 국제구호팀장, 김은미 이화여대 국제대학 원 교수, 성극제 경희대 국제대학원장, 현오석 한국개발연구원(KDI) 원장, 송경순 한국전문가컨설팅그룹(KECG) 대표

국제개발협력위원회는 실무업무의 보좌를 위하여 산하에 실무위원회와 소위원회를 두고 있다. 실 무위원회는 국제개발협력위원회에 올라 온 의제에 대한 사전검토와 함께 회의 결과에 대한 후속조 치를 맡고 있다. 소위원회는 특정과제의 수행을 위하여 필요한 경우에 운영되며, 현재는 지난 제5 차 국제개발협력위원회 후속조치로 통합평가소위원회(평가소위)를 운영하고 있다.

국제개발협력위원회의 역할은 정부의 $\mathrm{ODA}$ 정책 및 기본계획에 대한 심의 · 조정으로, 주요내용은 다음과 같다.

첫째, 국제개발협력위원회는 $\mathrm{ODA}$ 에 관한 종합정책과 제도개선 사항을 심의한다. 또한 정부의 $\mathrm{ODA}$ 예산을 보다 효율적으로 집행하고, 나아가 $\mathrm{ODA}$ 사업을 보다 잘 수행하기 위하여 끓임없이 정 책과 제도개선에 관한 과제를 제기하고 심의 · 확정한다.

둘째, 국제개발협력위원회는 각 부처에서 수립된 ODA 정책 및 기본계획을 심의 · 조정한다. 〈그림 1 과 같이 우리 정부의 $\mathrm{ODA}$ 정책체계는 유 · 무상 양자원조와 다자원조로 구분되며 유상원조는 기 
획재정부에서, 무상원조는 외교통상부에서 각각 담당한다 ${ }^{3)}$. 다자원조의 경우도 $\mathrm{IDA}, \mathrm{ADB}, \mathrm{AfDB}$ 등 국제금융기구에 대한 출연 · 출자는 기획재정부에서, UNDP, IAEA 등 UN기구에 대한 분담금 은 외교통상부에서 담당한다. 국제개발협력위원회는 이와 같이 이원적인 $\mathrm{ODA}$ 정책체계에서 중심 적 역할을 담당하며 정책의 일관성과 사업의 효율성을 높이는 기능을 수행한다.

\section{〈그림 1〉우리정부 ODA 정책체계}

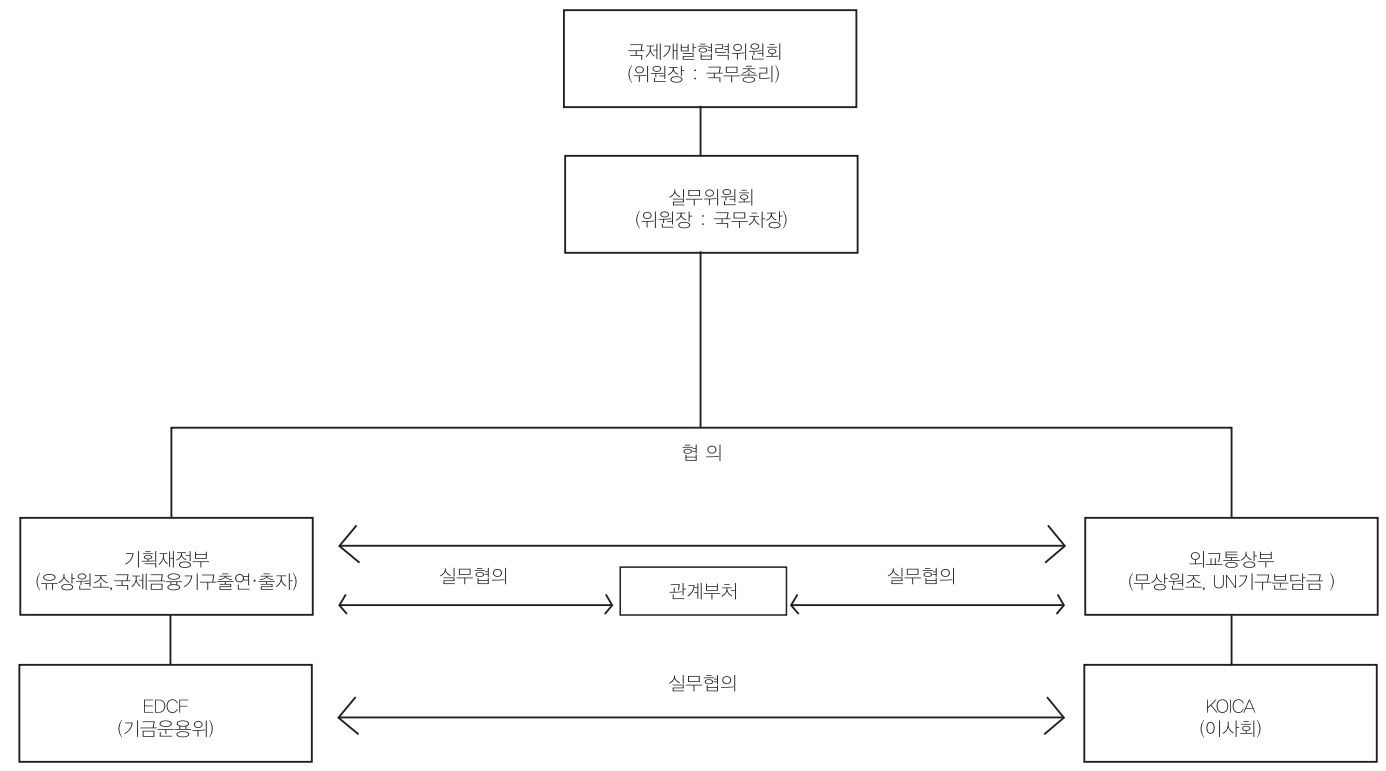

끝으로, 국제개발협력위원회는 ODA 정책과 사업 전반에 대하여 종합적인 평가를 수행한다. 〈그림 $2>$ 와 같이 국제개발협력위원회에서 심의 · 확정한 $\mathrm{ODA}$ 정책 및 기본계획은 각 부처와 관계 기관이 자신들의 정책과 사업으로 추진하고 그 추진결과에 대해서는 다시 국제개발협력위원회 평가소위가 통합평가를를 실시한다. 또한 위원회는 평가결과 피드백을 통해 평가교훈이 차기 정책 및 사업계획 수립에 반영되도록 한다.

국제개발협력위원회는 위에서 설명한 기본적인 역할 이외에도 ODA와 관련하여 필요하다고 여겨지 는 의제에 대하여 심의하고 있다.

3) 양자원조의 집행에 있어서는 유상(EDCF)의 경우 $100 \%$ 로 기획재정부에서 수행하는 반면 무상은 약 $80 \%$ 정도만 외교통상 부(KOICA)가 수행하고 나머지는 20여개 부처 및 기관으로 분담되어 있다.

4) 통합평가 실시는 2009.5.2 제5차 국제개발협력위원회의에서 결정사항으로, 평가소위 구성을 완료(7.30)하고 현재 (2009.9) 통합평가지침 제정을 준비하고 있다. 통합평가는 2010년에 시범실시 예정이며, 2011년부터는 본격적으로 실시 된다. 


\section{III. 위원회 활동현황}

〈그림 2〉 국제개발협력위원회 역할

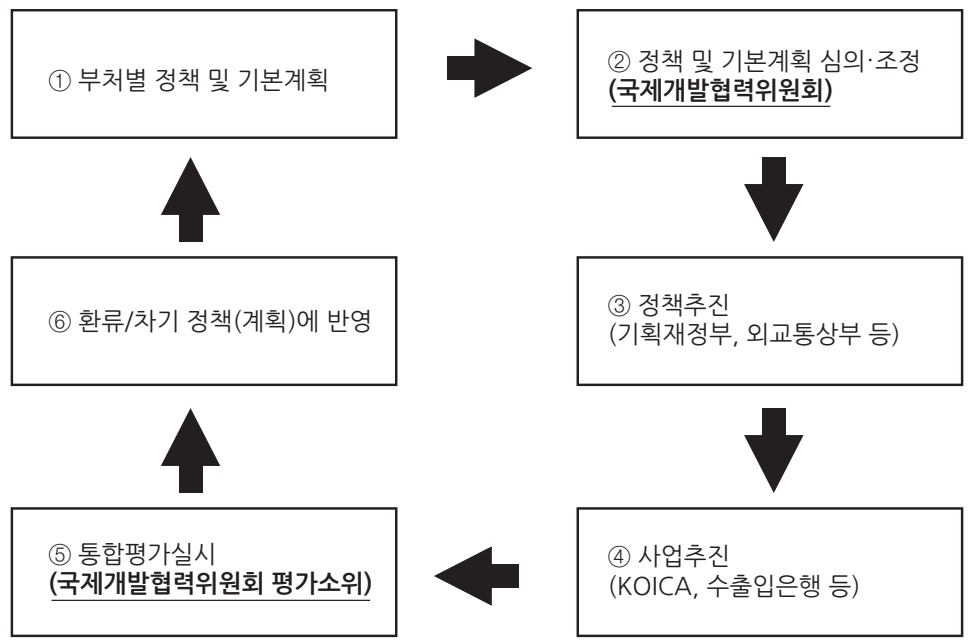

2006년3월2일 제1차 국제개발협력위원회가 열린 이래 지금까지 총 5 회의 국제개발협력위원회가 개최되었다. 위원회는 그 동안의 회의를 통하여 연간 $\mathrm{ODA}$ 추진계획, $\mathrm{ODA}$ 중기전략, 국별지원전 략(Country Assistance Strategy : CAS), ODA 규모 확대, $\mathrm{OECD}$ 개발원조위원회(DAC) 가입, $\mathrm{ODA}$ 선진화 추진(통합평가, 기본계획 및 통합 국별지원전략 수립, 비구속성 원조) 등을 의결하였 다. 각 회차별 주요결정사항은 〈표 2〉과 같다.

〈표 2〉 국제개발협력위원회 회차별 주요결정사항

\begin{tabular}{|c|c|c|c|}
\hline 회차 & 일자 & 주재 & 주요결정사항 \\
\hline 제1차 & 2006.3.2 & 국무총리 & $\begin{array}{l}\text { - '06년도 ODA 추진계획 확정 } \\
\text { - 해외긴급구호시스템 구축 } \\
\text { - ODA 대국민 홍보 강화 방안 수립 }\end{array}$ \\
\hline 제2차 & 2007.7 .20 & 국무총리 & $\begin{array}{l}\text { - '07년도 ODA 추진계획 확정 } \\
\text { - ODA 중기('O8-'10년간) 전략 수립 } \\
\text { - OECD 개발원조위원회(DAC) 가입 }\end{array}$ \\
\hline 제3차 & 2008.1 .8 & 국무총리 & $\begin{array}{l}\text { - '08년도 ODA 추진계획 확정 } \\
\text { - ODA 중기 국별지원전략(CAS) 수립 } \\
\text { - 언타이드 추진 및 개발경험공유 활성화 방안 수립 }\end{array}$ \\
\hline 제4차 & 2008.8 .14 & 국무총리 & $\begin{array}{l}\text { - 중기 ODA 규모 확대계획 수립 } \\
\text { - OECD 개발원조위원회(DAC) 가입 추진 } \\
\text { - 국제빈곤퇴치기여금 운용 추진 }\end{array}$ \\
\hline 제5차 & 2009.5.1 & 국무총리 & $\begin{array}{l}\text { - '09년 ODA 추진계획 ㅎㅘㅘ정 } \\
\text { - ODA 통합평가, 기본계획 및 통합 국별지원전략(CAS) } \\
\text { 수립, 언타이드 원조비율 제고 추진 }\end{array}$ \\
\hline
\end{tabular}


국제개발협력위원회는 매년 「연간 ODA 추진계획」을 심의·확정하고 있다. 의제로 상정하는 $\ulcorner$ 연간 $\mathrm{ODA}$ 추진계획」은 유·무상, 다자 ODA 사업을 포괄하는 종합계획이다.

또한, 국제개발협력위원회에서 결정하여 추진하였던 해외긴급구호시스템 구축(1차) 및 $\mathrm{OECD}$ 개발 원조위원회 가입(2차), 중기 국별지원전략(CAS) 수립(3차), 중기 $\mathrm{ODA}$ 규모 확대계획(4차), $\mathrm{ODA}$ 통합평가 추진(5차) 등은 국제개발협력위원회의 통합 - 조정 역할을 보여준 사례라고 볼 수 있다.

회차별 특징을 간략하게 살펴보면, 2006년3월2일 제1차 국제개발협력위원회는 처음 개최하는 회 의였던 만큼 우리 정부 ODA 현주소에 대한 종합적인 논의였다. 위원회는 ODA 규모 확대의 필요 성과 대국민 홍보 등을 통한 인지도 제고의 중요성에 대하여 동의하였다. 아울러, 아프리카 원조 확 대, 쓰나미 이후 우리정부의 긴급구호시스템 구축 등 당시 필요한 조치들을 결정하였다.

2007년 7월 20일 제2차 위원회는 국제사회에서의 우리 정부의 역할 과 ODA 체계 확립을 위한 회 의였다. 여전히 $\mathrm{ODA}$ 규모 확대의 필요성을 공감하였고, $\mathrm{OECD}$ 개발원조위원회(DAC) 가입을 위한 체제구축의 필요성이 언급되었다. 그리고 효과적인 $\mathrm{ODA}$ 추진을 위해 중기지원전략을 수립하고 전 문성을 강화 하기로 하였다.

2008년 1월 8일 제3차 위원회는 선진 공여국과의 원조조화(Harmonization) 및 수원국과의 정책 대화를 통한 프로그램 원조의 필요성 등 선진원조 추진에 대해 논의했다. ODA 국별지원전략(CAS) 을 수립하였고, ODA 기본 정책문서와 비구속성(Untied) 원조 추진도 결정하였다.

3차 위원회 이후, 국제개발협력위원회에 위기가 있었다. 2007년 7월 국무조정실은 「국무총리실 위원회 정비(2차) 계획 $\left.{ }^{5)}\right\lrcorner$ 을 세워 당시 운영 중인 국무총리 주재 49 개 위원회를 대대적으로 정비하 기로 했는데, 국제개발협력위원회도 그 대상이었다. 게다가, 2008년 2월 신정부가 들어서면서 국 제개발협력위원회를 담당하는 국무총리실의 조직과 인력이 개편되어 위원회는 몇 달간의 혼란기를 겪었다.

〈표 2〉의 주요 결정사항을 보면, 2,3 차 위원회에서 다루었던 의제들을 4,5 차 위원회에서 강화된 내용으로 다시 심의한 사실을 알 수 있는데, 그 까닭은 국제개발협력위원회가 국무총리실 정비대상 위원회로 검토되었다는 사실 등과 관련이 있다.

5) 국무조정실은 2006년 8월 「국무총리실 위원회 정비(1차) 계획」을 수립하고 국무총리 주재 54개 위원회에 대한 운영 실 태를 조사, 실적이 저조한 6 개의 위원회는 폐지하고 전문「기술적 사항의 위원회는 위원장 직급을 하향조정했다. 그리고 2007.7월 국무조정실은 한번더「국무총리실 위원회 정비(2차) 계획」을 추진하였다. 
결국 국제개발협력위원회는 2008년 4월 존치 필요성이 인정되어 2008년 8월 14 일 제4차 위원회 로 부활한다. 폐지의 위기에서 소생한 뒤 개최된 제4차 국제개발협력위원회에서는 GNI 대비 ODA 규모를 2012년 0.15\%, 2015년 0.25\%로 확대하기로 결정하였다. $0.15 \%, 0.25 \%$ 로의 확대 결정 은 구체적인 달성 목표를 수립하였다는 점에서 큰 성과로 평가되고 있다. 또한 4차 위원회의 회의 진행방식과 관련하여 흥미로운 사실은 합의된 의제로 토론을 진행하였던 종전의 방식과 달리, ODA 규모 확대 의제에 대하여 기획재정부와 외교통상부가 서로 상반된 의제로 발제하고, 위원장과 위원 들의 찬 · 반 토론을 통해서 최종 결정을 하였다는 점이다.

최근(2009.5.1)에 개최한 제5차 위원회는 규모 확대에 따른 ODA 선진화를 주요 의제로 다루었다. 통합평가체제 구축, $\mathrm{ODA}$ 기본계획 및 통합 국별지원전략 $(\mathrm{CAS})$ 수립, 비구속성 원조비율 제고가 그것이다. 5 차 위원회의 특징은 세계위기(금융, 물부족, 기후변화 위기)와 $\mathrm{ODA}$ 를 함께 고려하였다 는 점이다. 정부는 세계위기 상황 속에서도 $\mathrm{ODA}$ 규모 확대는 차질 없이 진행하고, ODA 사업을 세 계위기 상황과 정부의 정책사업과 조화롭게 연계하여 효과적으로 추진하기로 하였다.

\section{IV. 향후계획}

현재 제 5 차 국제개발협력위원회의 후속조치는 활발하게 이루어지고 있다. 세계금융위기, 기후변 화, 물 부족 문제 등을 고려하여 정부정책사업과 $\mathrm{ODA}$ 를 연계할 수 있도록 관계부처가 협력하고 있 닫) 또한 통합평가 추진을 위하여 2009년 7월 8일 실무회의를 열고, 7월 30일 통합평가 수행을 위한 평가소위를 구성하였다. 아울러, ODA 기본계획 및 통합 국별지원전략(CAS) 수립을 위해 10 월에 실무위원회를 추가로 열 예정이다.

국제개발협력위원회 결정사항에 따르면, 2015년 우리나라는 GNI 대비 $0.25 \%$ 에 해당하는 예산을 $\mathrm{ODA}$ 로 집행할 것이다. 만일 2015년에 정부가 ODA 규모를 예정대로 늘린다면, 추정해 보건대 현 재수준의 3 배 이상(약 3.5 조원 $\left.{ }^{7)}\right)$ 이 될 것이다. 이는 매우 고무적인 일로서, 국제사회에서 우리정부 의 책임분담과 역할수행을 가시적으로 담보할 수 있는 시점이 될 것이다.

그러나 되돌아 보건데, 우리 정부는 $\mathrm{OECD}$ 국가 $\mathrm{ODA}$ 평균(0.25\%)수준으로 규모를 확대하고 $\mathrm{OECD}$ 개발원조위원회(DAC) 가입 등을 추진하면서, 실질적인 노력보다는 형식적인 $\mathrm{ODA}$ 발전에 더욱 관심을 가져왔다는 평가를 지나칠 수 없다. 효율적인 $\mathrm{ODA}$ 추진이 진정으로 필요한 시점이다.

6) 2009.7.8 제5차 실무위원회는 ODA를 정부의 정책사업(4대강 살리기, 저탄소 녹색성장, 기후변화 등)과 효과적으로 연계 하는 방안을 논의하고 부처간 협력강화를 통하여 추진 중이다.

7) 2008년 ODA 실적을 기준으로 한국은행 제시 평균 물가상승률을 활용하여 2015년 GNI를 추정한 금액의 0.25\% (원화금액) 
이러한 점을 보완하고자 국제개발협력위원회를 운영하고 있는 국무총리실은 향후 국제개발협력위 원회의 $\mathrm{ODA}$ 정책적 기능을 지속적으로 강화해 나갈 방침이다.

\section{참고문헌}

국무조정실. 2005. 「대외원조 개선 종합대책」

국무조정실. 2007. 「위원회 정비(2차) 계획」

대통령령 제20724호. 2008.2.29.「국제개발협력위원회 규정」

주 $\mathrm{OECD}$ 대표부. 2009. 「공적개발원조(ODA) 정책에 대한 $\mathrm{OECD}$ 논의동향」

한국국제협력단(KOICA). 2008.『국제개발협력의 이해』. 한울

한국국제협력단(KOICA). 2008 『개발협력평가 가이드라인』

한국수출입은행. 2009. 『 $\mathrm{EDCF}$ 사후평가보고서 작성 가이드라인』

대외경제정책연구원(KIEP). 2008. 『우리나라 대외원조역량의 현황과 과제』

제 1 5차 국제개발협력위원회 안건 및 회의록

제1 5차 국제개발협력실무위원회 안건 및 회의록 